\title{
Concurso Nacional «Diseño Arquitectónico de una Caleta Modelo»
}

\section{$7^{\text {ER LUGAR CALETA TUMBES }}$ UNIVERSIDAD DE CHILE}

Proyecto: Plataforma Productiva Tumbes.

Autores: Víctor Alegría C. + Javier Moya $O$.

+ Daniel Meza C. + Félix Salinas D.

Institución: Universidad de Chile.

Ubicación: Tumbes, VIII Región, Chile.

Superficie interior: $863 \mathrm{~m}^{2}$.

Superficie exterior: $1.304 \mathrm{~m}^{2}$.

Materialidad: Hormigón, madera y teja asfáltica.
El Gobierno de Chile, a través de la

ESubsecretaría de Pesca, de la Dirección de Obras Portuarias y del Servicio Nacional de Pesca, organizó el Concurso Nacional "Diseño Arquitectónico de una Caleta Modelo»"[1], dirigido a las Escuelas de Arquitectura de las universidades chilenas.

El objetivo del Concurso consistió en el diseño del anteproyecto de las obras terrestres de las caletas de Tumbes, Coliumo y el mercado fluvial del río Maule en la Región del Maule y del Biobío, con el objetivo de no sólo reconstruir tras el terremoto del pasado 27 de febrero, si no que de crear una nueva infraestructura que mejore las condiciones de trabajo de los pescadores, aprovechando las ventajas turísticas de estas zonas.

Cabe destacar que la catástrofe dejó un saldo de 69 caletas afectadas, de las cuales 37 resultaron dañadas en sus edificaciones e infraestructura portuarias, siendo intervenidas y reconstruidas tanto por iniciativas privadas como públicas dentro de un plan de intervención al año 2014.

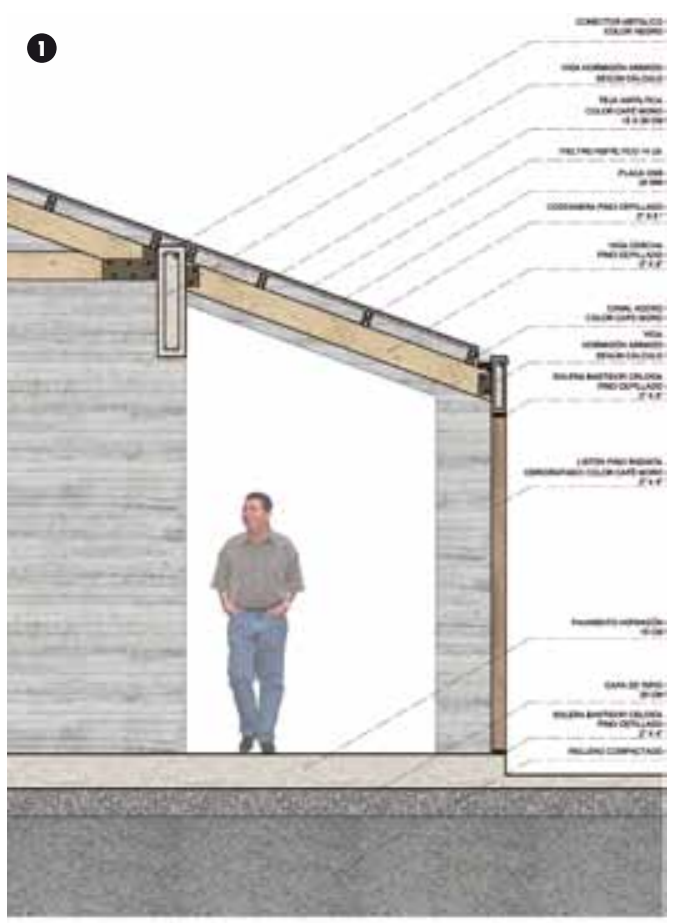

(5) 
1. Escantillón.

2. Planta general del proyecto.

2

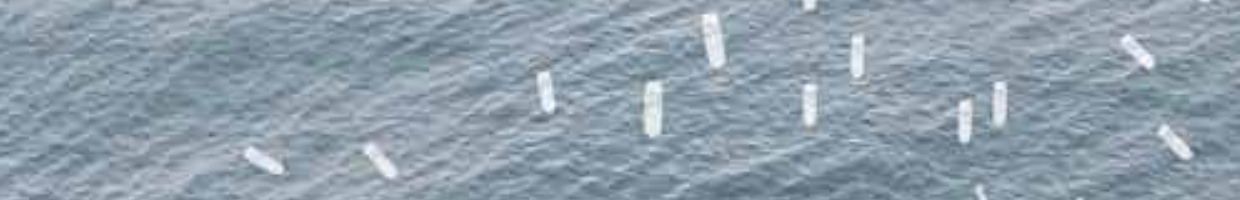

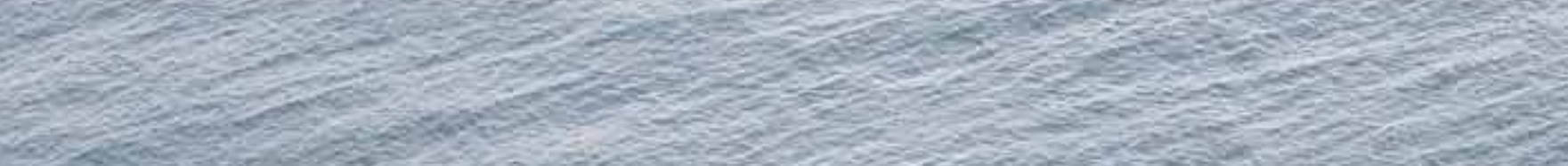

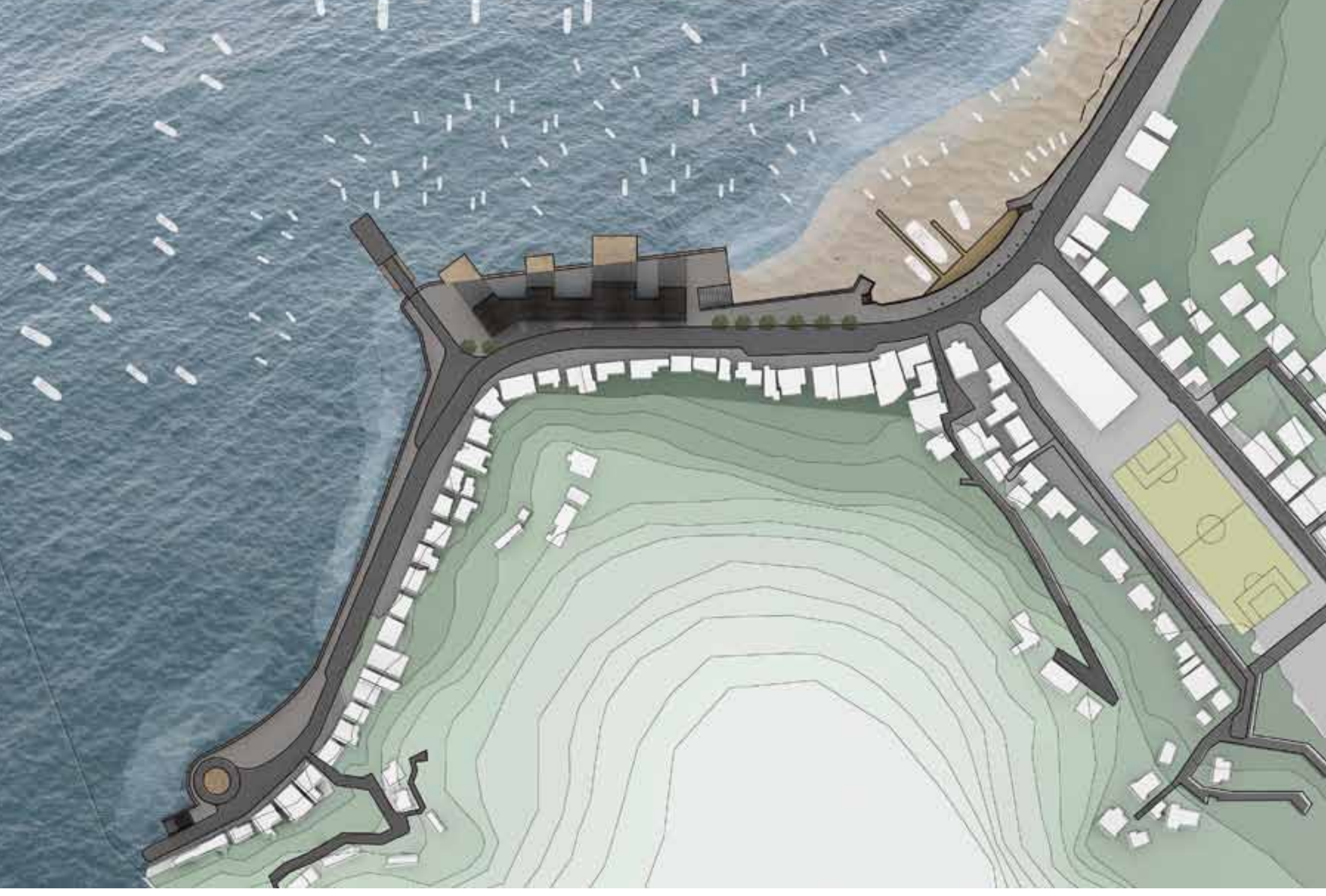


3. Planta del proyecto.

4. Vista general del proyecto

5. Corte longitudinal.
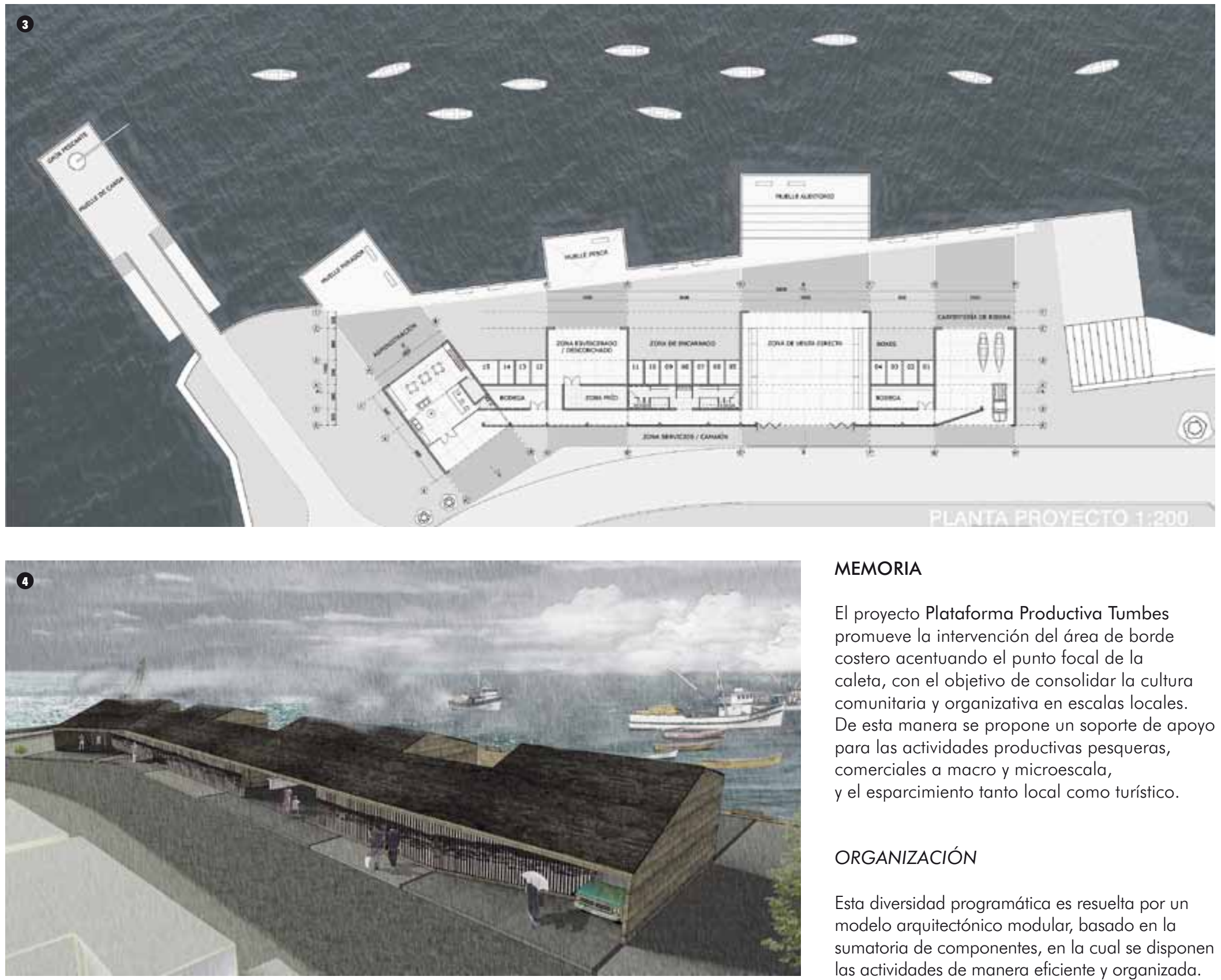

\section{MEMORIA}

El proyecto Plataforma Productiva Tumbes promueve la intervención del área de borde costero acentuando el punto focal de la caleta, con el objetivo de consolidar la cultura comunitaria y organizativa en escalas locales. De esta manera se propone un soporte de apoyo para las actividades productivas pesqueras, comerciales a macro y microescala,

y el esparcimiento tanto local como turístico.

\section{ORGANIZACIÓN}

Esta diversidad programática es resuelta por un modelo arquitectónico modular, basado en la sumatoria de componentes, en la cual se disponen las actividades de manera eficiente y organizada.

(5)

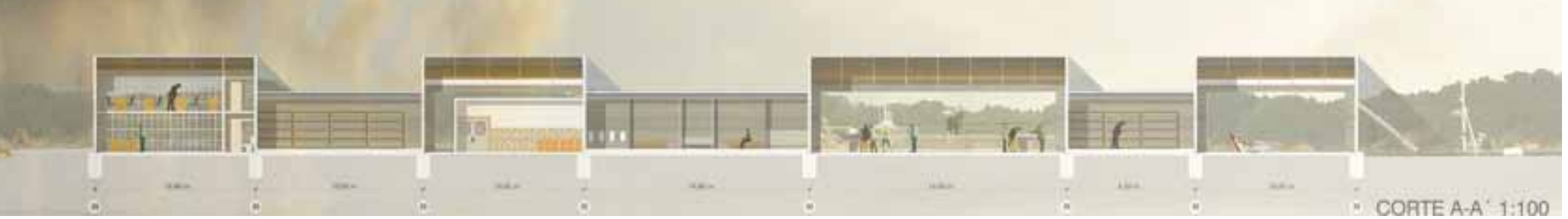


6. Elevación norte.

7. Elevación sur.

8. Elevación oriente.

9. Elevación poniente.

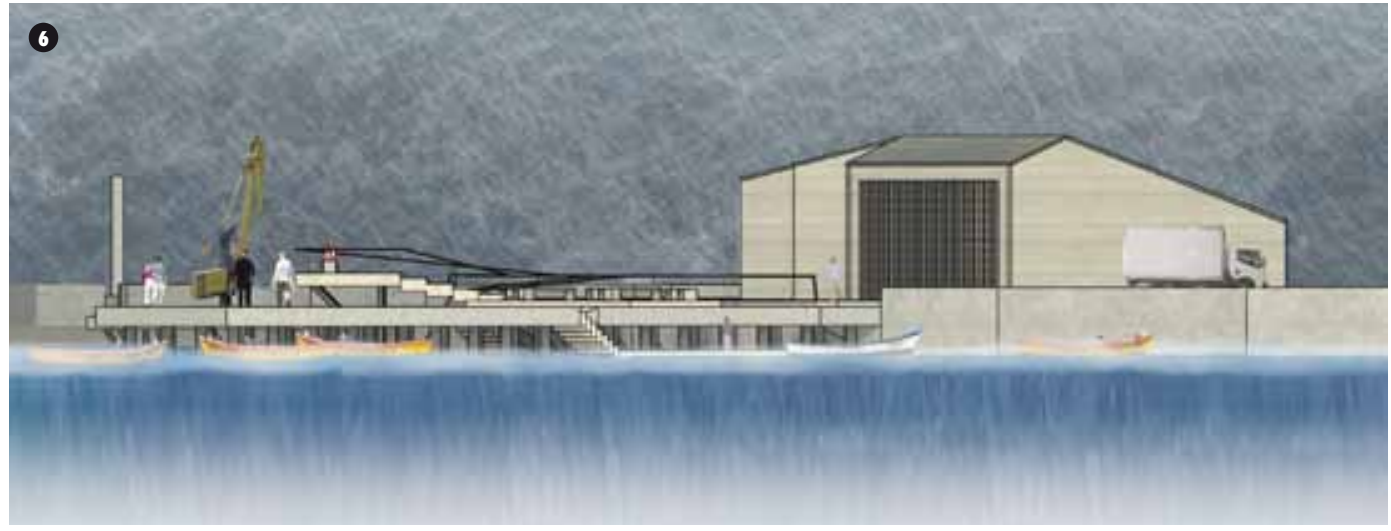

\section{MODELO}

El sistema de componentes propuesto permite la prefabricación de la totalidad del proyecto, siendo un modelo replicable, adaptando su componentes a las necesidades de cada comunidad.

Plataforma Productiva Tumbes propone un componente básico que conjuga el funcionamiento de dos subcomponentes, uno pequeño con recintos del tipo bodega y otro grande del tipo galpón destinados a cada actividad importante, como mercado, taller o administración.

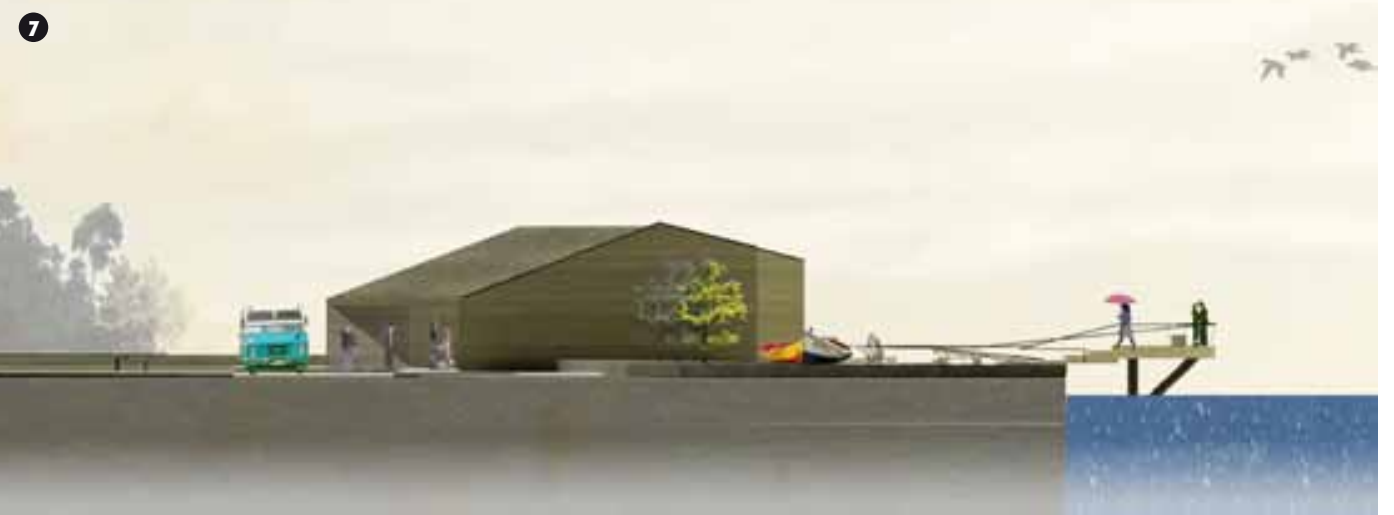

El volumen final busca reinterpretar de manera contemporánea la arquitectura tradicional de las pequeñas localidades, con techo a dos aguas, fachada continua y corredor exterior cubierto, relacionando la ciudad con el mar mediante espacios exteriores de uso flexible, que integran actividades productivas, comerciales y recreacionales.
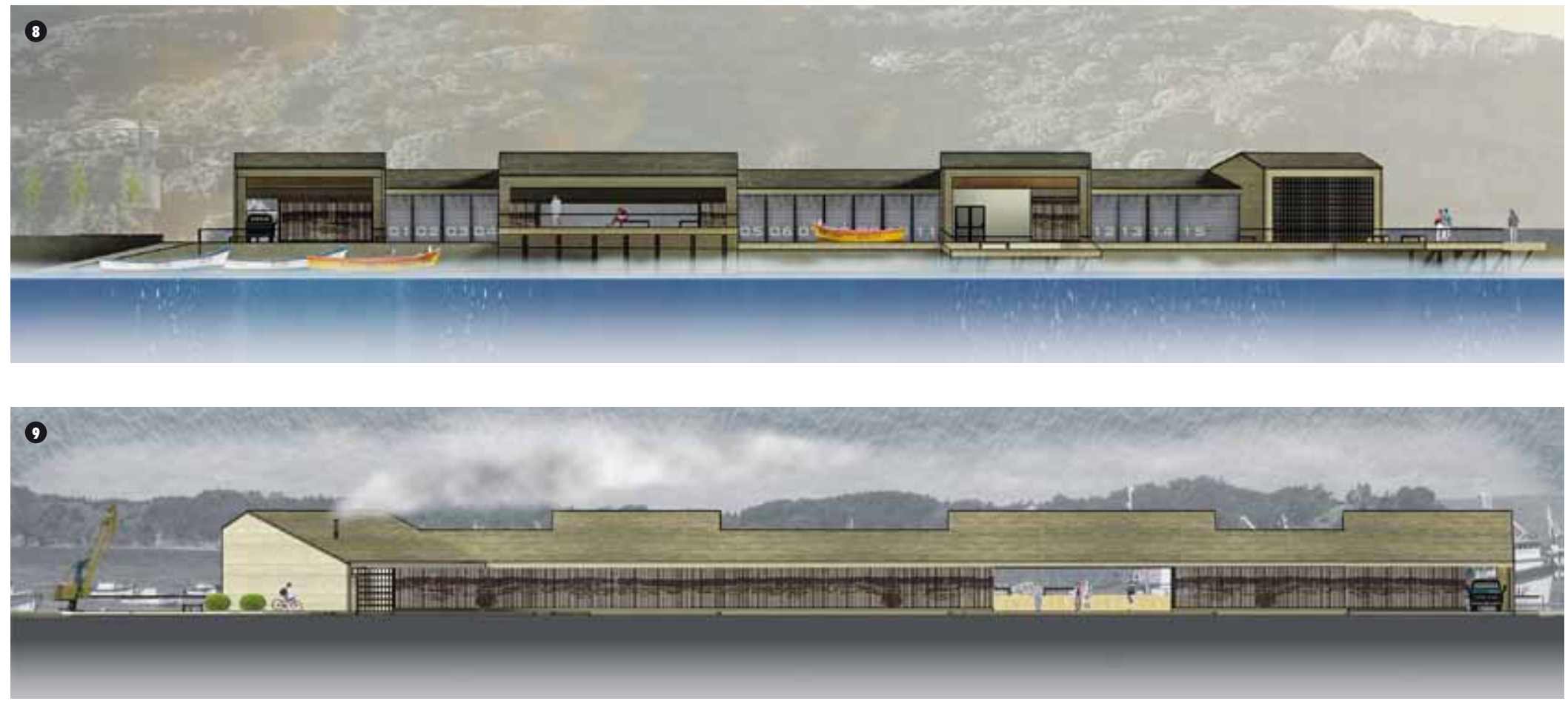
10. Vista interior del proyecto.

11. Vista general del proyecto.

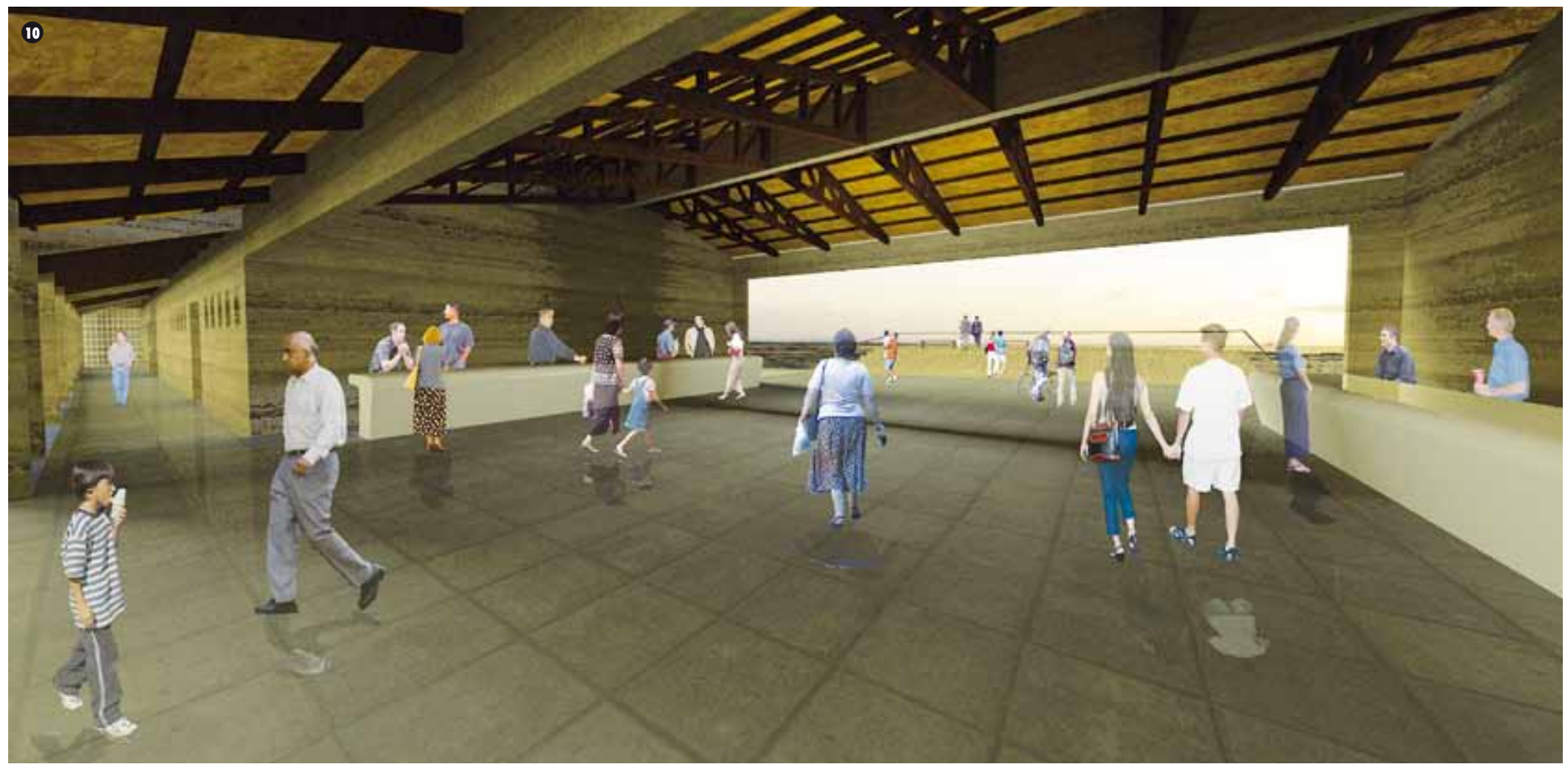

\section{(1)}

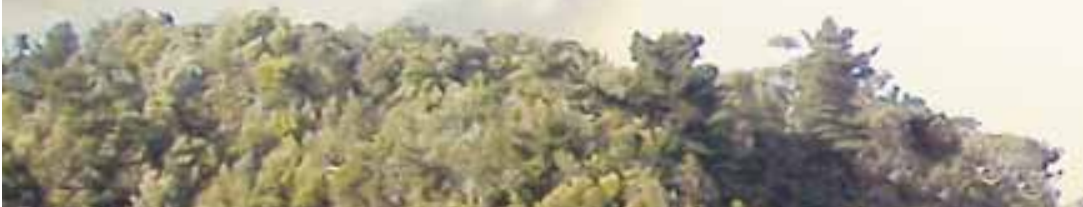

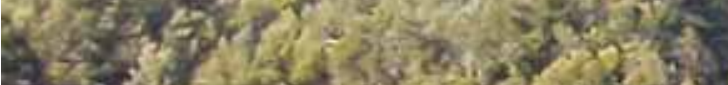

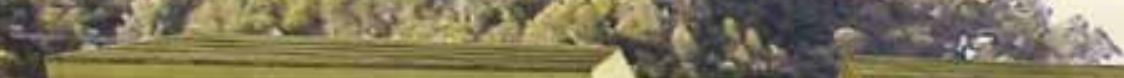

$x=2=1.12$ 


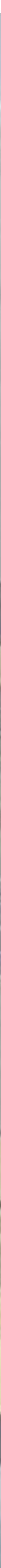

